\title{
The Impact of Pragmatic Markers Acquisition and Phonological Awareness on Word Choice in Translating Literary Texts from Arabic into English
}

\author{
Salwa Alwafai ${ }^{1}$ \\ ${ }^{1}$ Department of English, College of Arts, Imam Abdulrahman Bin Faisal University (IAU), Saudi Arabia \\ Correspondence: Salwa Alwafai, Assistant Professor of Lingustics and Translation Studies, Department of \\ English, College of Arts, Imam Abdulrahman Bin Faisal University (IAU), Saudi Arabia. E-mail: \\ salwawafai@msn.com
}

Received: January 21, 2019 Accepted: February 14, 2019 Online Published: April 6, 2019

doi:10.5539/ijel.v9n3p95 URL: https://doi.org/10.5539/ijel.v9n3p95

\begin{abstract}
Pragmatic markers, either primary or secondary, contribute to the specificity of languages and are sensitive on being translated. This study traces the use of well, the commonest pragmatic marker in the English discourse, in a corpus of translated Arabic novels. The study, too, addresses the influence of the translators' phonological awareness on their word choices, in the same corpus. Adjacent consonants, consonant-starting and quarter-syllabic words are studied in four groups: free writing of native authors as a control group (G1), literary translations by native English translators (G2), literary English translations by Arabic translators (G3) as well as literary English translations by joint effort (native-speaking and non-native-speaking translators) [G4]. The findings are statistically compared using one-way ANOVA test. Results show a statistically significant difference in the use of the pragmatic marker well and in the use of the three phonological patterns among the four groups. The findings are interpreted and implications are offered for the pragmatic gap and linguistic competence between native-speaking and non-native-speaking translators.
\end{abstract}

Keywords: pragmatic markers, translation studies, linguistic competence, literary translation, phonology

\section{Introduction}

Mateo (2014) emphasizes that translator's phonetic and pragmatic awareness are instrumental to rendering a successful translation. In English, pragmatic markers have a variable and context-bound character. Their meaning therefore cannot be described in the same way as lexical elements which have a more stable lexical meaning (Aijmer, 2015). This is not the case in Arabic. Phonetically speaking, phonotactic probability and phonological awareness might influence several cognitive processes (Vitevitch \& Luce, 2005).

This study uses literary translation materials, as a rich medium for measuring language production, among native-speaking and non-native speaking translators with regard to pragmatic markers acquisition and phonological awareness. The studied language pair is Arabic-English. All the studied novels are originally written in Arabic and are translated into English. Both versions are used in this study. The first hypothesis postulates that mastering the use of primary pragmatic markers, e.g., well, is variable among native-speaking and non-native speaking translators. This study hypothesizes also that phonological awareness affects word choices among the studied groups of translators. The third hypothesis postulates that both incompetent use of well, as a prototypical pragmatic marker, and deficient use of phonologically problematic words for Arabic learners affect the overall readability of the rendered translation among the studied groups.

The output of this paper, other than investigating the validity of the three hypotheses mentioned above, is a lexicon of difficult-to-learn words L1 Arabic translators usually avoid regardless of the frequency of using such words and familiarity to target readers.

The rest of this paper is organized into five sections. Section 2 briefs the theoretical background and the basic neurolinguistics evidence which supports the hypotheses of the present study. The methodology of this research is explained in the third section. Section 4 displays results and findings. Discussion of the findings and relating them to that of the relevant literature is detailed in Section 5. The final section presents the concluding remarks and recommends possible directions for future research. 


\section{Theoretical Background}

Rinne et al. (2000) concludes that translation into a non-native language is cerebrally more demanding task than translating into a native language. Mateo (2014) emphasizes that translator's phonetic and pragmatic awareness are instrumental to rendering a successful translation. Therefore, we investigate the influence of two variables on the quality of the rendered translation. In this section, we introduce a brief introduction about pragmatic marker as well as phonological awareness and phonotactic probability.

\subsection{Well as a Prototypical Pragmatic Marker}

Pragmatic markers and discourse markers are either primary or secondary. A primary pragmatic marker is the most general in its class, while the secondary markers of the class carry a more specific relationship (Norrick, 2009). Pragmatic markers do have a variable and context-bound character. They, however, get their meaning through 'dynamic sense-making' in local situated contexts as explained by the theory of meaning potentials. This holds true especially in corpus-based pragmatic investigations (Aijmer, 2015; Norrick, 2009). We study well as a primary pragmatic marker in English. In Modern Standard Arabic, the corresponding primary pragmatic markers are 'hassanan', 'beltaba' and 'taba'an'. However, the use of Arabic primary pragmatic markers is much lesser than the use of primary pragmatic markers in English.

Well, as a pragmatic marker, poses versatile and dynamically rich meaning which is activated according to the pursuit of negotiating situated interpretations. Well functions conventionally at the levels of grammatical construction, phonology, syntax, semantics, prosody, pragmatics, discourse, etc., which represents a generalization about speakers' grammatical knowledge. However, the complex functional usages, repetition frequencies as well as the ontolexical link between form and function add up to creating the big picture of the speaker's sociolinguistic background. The major functionality of well can be attributed to possessing a core meaning which is underspecified and becomes enriched in context and to possessing a prototypical meaning from which other uses can be derived. Well can also characterize opening a discussion, challenging, hedging, or modifications the users are prone to make. Typically, well co-occurs with pauses or with phrases such as I guess or I don't know (Cuenca, 2008).

Other "micro-functions", or subsenses, have been also proposed (Aijmer, 2015):

- Word search and self-repair: well is then used in a falling or rising tone.

- Projecting a new turn: well is a powerful projection device pointing forwards to the next turn or discourse unit.

- Transition according to an agenda: being used as a contextualization cue, well signals a change of topic or speech act according to an agenda or an interpretative frame

- Transition to a quotation: well makes the description more vivid and emotional. There, it typically collocates with a form of say or think and occasionally other verbs such as 'wonder' and 'ask'.

Translating narrative discourses in literary texts and in verbal communication warrants a creative attitude in using pragmatic markers (Peterlin \& Moe, 2016; Metsä-Ketelä, 2016; Alós, 2016). Therefore, introducing such pragmatic markers to the translated Arabic novels, or literature, should be attempted whenever indicated in order to enhance the readability of the translated texts (House, 2013; Nord, 2014). Arabic translators, accordingly, should become more familiar with the use of pragmatic markers on translating into English.

Therefore, we correlate the incidence of occurrence of 'well' in the translated novels to the frequency of using Arabic primary pragmatic markers in the original text.

\subsection{Phonological Awareness and Phonotactic Probability}

Based on the impact of the mother tongue, English learners face some problems in accepting and phonetically pronouncing, among many, some minimal pairs, consonant clusters and sequential consonant articulations (Leather, 1999, Roberts \& Meyer, 2012). Certain sounds and sound combinations are frequent in Arabic but they are totally absent in English and vice versa. It is evident that such disparity influences language learning and production. Reviewing neurolinguistics evidence, Veroude et al. (2010) conclude that the left supramarginal gyrus, the pars opercularis and left supplementary motor area as well as the left insula and left posterior superior and middle temporal gyri are responsible for phonological acquisition of new vocabulary. Phonological awareness skills predict of literacy ability because they allow recognition of the constituents of words that facilitate letter to sound mapping. Kuo and Anderson (2010) introduced their structural sensitivity theory (SST) to explain the (in)ability of bilinguals to track the distribution of linguistic units of more than one language, re-conceptualize cross-language transfer and to define the impact of bilingualism on phonological awareness. Kuo and Anderson (2012) expand the SST further to go beyond infancy and extend to the acquisition of a new language. 
This divergence enabled the newer version of SST to provide insights on the adopted phonotactic patterns among bilingual learners. They conclude that the salience of segmental units, phonological regularity and orthography affected the extent to which phonological awareness is enhanced.

Phonotactic probability refers to the frequency with which phonological segments and sequences of phonological segments occur in the words of a given language (Vitevitch \& Luce, 2005). Phonological segments or sequences of phonological segments that occur frequently in certain positions in a given language are said to be high in phonotactic probability, whereas less frequently occurring phonological segments and sequences of phonological segments are said to be low in phonotactic probability. Learning of novel words in adults is influenced by phonotactic probability (Storkel, Armbruster, \& Hogan, 2006).

Moreover, Finn and Kam (2008) suggest that prior linguistic knowledge, with regard to English phonotactics and phoneme co-occurrence, can interfere with learners' abilities to segment words from running speech using purely statistical cues at initial exposure. Earlier, Munson et al. (2005) demonstrated vocabulary size may mediate the influence of phonotactic probability on nonword repetition, perhaps due to its influence on the ongoing refinement of phonological categories. Pertinently, studies on mental graphemic representations have also reported similar findings (Badecker, 1996; Endress et al., 2010; Parra et al., 2011; Wolter \& Apel, 2010).

Failure to modify these phonotactic constraints would have resulted in the impermissible sequences (e.g., cat/z/). Phonemic errors occurring in producing non-English sequences even at advanced stages of articulatory motor processing are susceptible to correction. This is simply because phonotactic constraints have no corresponding acoustic-articulatory motor pathways which are important for phonetic perception. Longer words will pose greater problems because they increase the number of sublexical elements that are simultaneously being processed. This increases the opportunity for these elements to induce errors by interacting with each other and their various associated sublexical elements. Similarly, Dutch speakers systemically give the letter " $x$ " the same pronunciation regardless of its location in the word. Accordingly, the set of "example, anxiety, anxious, and extreme' would have no difference for most of them. Arabic and Spanish speakers pronounce sp- and stconsonant clusters as esp- and est- in splash and stadium. They are also inclined to utter the rolling or trilled / $\mathbf{r} /$ sound. It is difficult for them to pronounce the /r/ sound properly (e.g., friend, Arabic, rare, drill...etc.). The monosyllabic and disyllabic words which contain consonant clusters and are minimal pairs are easier to pronounce Examples include smear and steer, or wasps and wisped. However, the situation aggravates in polysyllabic words such as disgraced, emasculate, excrescent, eschatological, squaw, and extraditable. Given the complexity of the latter set of words, which included other predisposing factors, may account for the paucity of their use in the English writings/translations of the Arabs (Kenworthy, 1987).

Defining lexical phonological neighbors as familiar words that differ from the target word by a single phoneme addition, substitution or deletion, Storkel et al. (2006) suggest that new words having a large number of lexical phonological neighbors appear to be learned faster than new words with a low-density lexical neighborhood. Moreover, lexical-semantic frequency, imageability and phonological neighborhood effects seem to contribute to learning difficulties of new L2 vocabulary (Nadeau, 2001).

Most phonetic studies focus on verbal tasks and neuroimaging of cerebral changes. However, the written text can be also a medium for production task given that corpus tools enable, now more than ever, transcription and transliteration of words to universal codes regardless of the diverse writing systems of the studied languages. English and Arabic languages belong to a phoneme-grapheme writing system in which phonemes are represented by graphemes. However, their writing systems differ in a number of ways. First, English is alphabetic and Arabic is consonantal. Second, the respective writing systems are also different. The degree of transparency in Arabic is, on the one hand, consistent with a 1:1 phoneme-grapheme representation, and so the sound-symbol correspondences are relatively transparent. On the other hand, English has inconsistent and more complex representations, and so the sound-symbol correspondences are relatively opaquer than in Arabic (Saigh \& Schmitt, 2012). Further, Arabic speakers' pronunciation difficulties in rendering English sounds may be categorized into mild, moderate, and extreme. However, we use a unified web-based phonotactic probability calculator, Aljasser and Vitevitch (2018) developed, in which both Modern Standard Arabic and English are integrated.

Therefore, we hypothesize that L1 Arabic and L1 English translators differ in their use of phonotactic characteristics according to the different phonetic perception of words.

\section{Methodology}

This study aspired to check the frequency of using the primary pragmatic marker well in 19 English translations of Arabic novels. A primitive phase aimed to provide basic insights and reference measures. We extracted corpus-based distributional measures of well in megacorpora (British National Corpus [BNC] and American 
Spoken corpus and enTenTen15). Both measures were compared to the free writing of the native translators (G1).

This study hypothesized also that phonological awareness and phonotactic probability affect word choices among the studied groups of translators. Systematically reviewing the relevant studies on new vocabulary acquisition and phonetic difficulties for L1 Arabic learners, we compiled a list of phonetically problematic words (PPW) and measured their frequency in the above mentioned megacorpora. We also retrieved WordNet's familiarity score. Summed phoneme probabilities and summed biphone probabilities of each lemma were measured by KU's web-based phonotactic probability.

Phase 2 started off with checking the findings of phase 1 by native-speaking linguists. On validating the findings of phase 1, we conducted the two experiments of phase 2 . We first preprocessed and cleaned the data (the 19 translated novels). We then compiled a main corpus which consisted of four major subcorpora representing four groups: (G1) free English writing as a control group; (G2) English translations of Arabic literary works by native speakers; (G3) English translations of Arabic literary works by non-native- speaking translators; and (G4) joint translation works. The four corpora represented samples of modern literary works in English. For all the imported texts, UTF-8 files were used to be compatible with the software programs: Content Analysis Software ${ }^{\circledR}$, AntConc and Sketch Engine. After the data became ready for analysis, the first experiment measured frequencies of using "Well" in the four subcorpora. For conducting the second experiment, pre-determined phonemic syllables were used to generate a list of words which can test the phonetic hypothesis. The generated wordlist was then computationally bootstrapped for measuring the incidence of occurrence in the four groups at the unit level (novel) and at the group level (G1-G4). Eventually, a lexicon (Appendix 1) of the phonetically problematic words (PPW) for Arabic translators was exported. One-way ANOVA tests with post-hoc Tukey HSD tests were performed to measure the variance between the studied groups.

\section{Results}

The findings of this study are viewed in two consecutive phases. Phase 1 pertains to the findings extracted from the general megacorpora. Table 1 displays the distributional usage of collocates and near-synonyms of well in BNC and enTenTen15. 
Table 1. Distributional usage of collocates and near-synonyms of well in BNC and enTenTen15.

\begin{tabular}{|c|c|c|c|}
\hline BNC & & enTenTen15 & \\
\hline Not & 0.741 & Much & 0.703 \\
\hline Also & 0.725 & Properly & 0.687 \\
\hline Now & 0.721 & Now & 0.684 \\
\hline Actually & 0.721 & Even & 0.681 \\
\hline Just & 0.720 & All & 0.675 \\
\hline Only & 0.710 & Not & 0.663 \\
\hline Never & 0.707 & Only & 0.663 \\
\hline All & 0.695 & Actually & 0.658 \\
\hline Then & 0.690 & There & 0.658 \\
\hline Always & 0.687 & Alone & 0.656 \\
\hline Here & 0.679 & Just & 0.655 \\
\hline Already & 0.670 & Far & 0.654 \\
\hline Probably & 0.659 & Here & 0.652 \\
\hline Usually & 0.655 & Also & 0.649 \\
\hline There & 0.653 & Maybe & 0.649 \\
\hline Still & 0.645 & As & 0.645 \\
\hline First & 0.645 & Again & 0.643 \\
\hline Ever & 0.641 & Probably & 0.642 \\
\hline Again & 0.639 & Soon & 0.638 \\
\hline Simply & 0.634 & Long & 0.636 \\
\hline Once & 0.628 & Enough & 0.635 \\
\hline Often & 0.627 & Finally & 0.631 \\
\hline Even & 0.619 & Really & 0.631 \\
\hline Either & 0.617 & Else & 0.626 \\
\hline Much & 0.601 & Ever & 0.625 \\
\hline Properly & 0.596 & Already & 0.624 \\
\hline Certainly & 0.595 & Always & 0.623 \\
\hline Normally & 0.585 & Once & 0.622 \\
\hline Really & 0.584 & Currently & 0.620 \\
\hline Yet & 0.580 & Especially & 0.618 \\
\hline About & 0.573 & $\mathrm{Up}$ & 0.618 \\
\hline Therefore & 0.571 & Likely & 0.617 \\
\hline Perhaps & 0.562 & First & 0.616 \\
\hline Thus & 0.559 & Quickly & 0.615 \\
\hline Together & 0.558 & Out & 0.615 \\
\hline Sometimes & 0.555 & Usually & 0.615 \\
\hline Soon & 0.552 & Then & 0.614 \\
\hline Generally & 0.550 & Yet & 0.611 \\
\hline Quickly & 0.548 & So & 0.607 \\
\hline Easily & 0.548 & Certainly & 0.607 \\
\hline Recently & 0.544 & Still & 0.607 \\
\hline Clearly & 0.538 & Definitely & 0.604 \\
\hline Enough & 0.537 & Fully & 0.604 \\
\hline Immediately & 0.532 & Right & 0.604 \\
\hline That & 0.529 & Instead & 0.600 \\
\hline As & 0.516 & Easily & 0.599 \\
\hline So & 0.516 & Regularly & 0.598 \\
\hline Eventually & 0.515 & Clearly & 0.597 \\
\hline Far & 0.513 & Too & 0.597 \\
\hline Merely & 0.513 & Generally & 0.596 \\
\hline Frequently & 0.511 & Normally & 0.595 \\
\hline Rarely & 0.500 & Together & 0.595 \\
\hline Finally & 0.499 & Effectively & 0.593 \\
\hline Carefully & 0.498 & Never & 0.593 \\
\hline Previously & 0.497 & No & 0.593 \\
\hline Currently & 0.495 & Therefore & 0.590 \\
\hline Directly & 0.492 & Eventually & 0.590 \\
\hline Alone & 0.491 & That & 0.589 \\
\hline Hardly & 0.489 & Perhaps & 0.588 \\
\hline
\end{tabular}


As Table 1 shows, the distributional usage of collocates and near-synonyms of "Well" in the BNC is associated, most often, with not, also, now, actually, just, only, never, all and then. The findings from enTenTen 15 suggest, instead, much, properly, now, even, all, not, only, actually, and there. Therefore, there is no consensus on the prototypical usage of well as a pragmatic marker. However, it is evident that well should be associated with adverbs and particles. Figure 1 visualizes the collocated and near-synonyms of well incidence in G1.

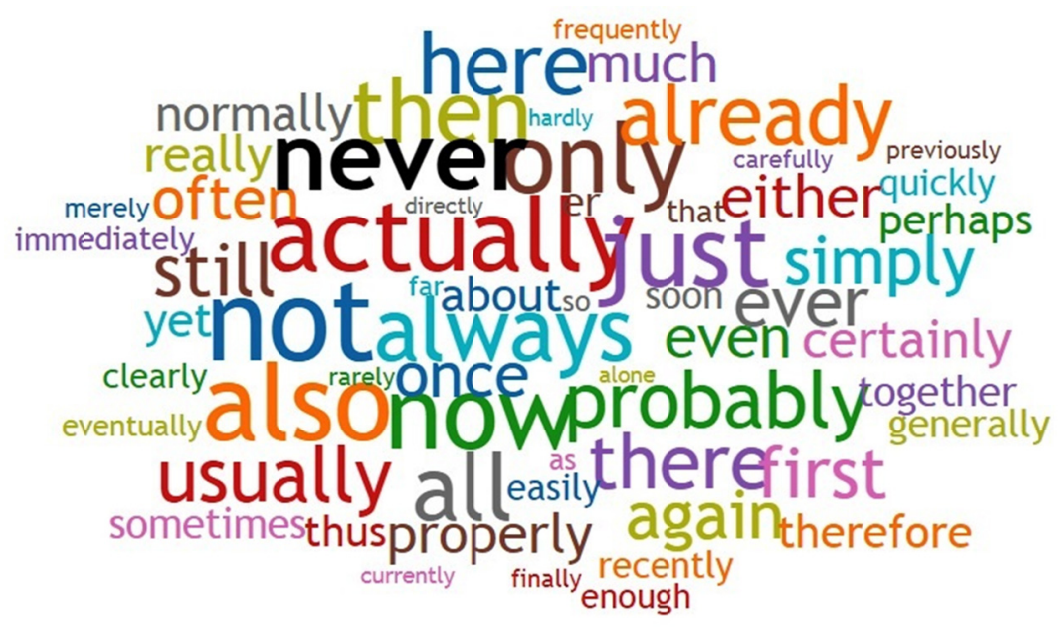

Figure 1. Word cloud visualizing the collocated and near-synonyms of well incidence in G1

For phase 2, an inclination of using well and the would-be PPWs is observed, which is significantly different among the four studied groups. True to the native English speakers' predilection (G1 and G2), the incidence of using such a set of words is much greater than in the writings of the non-native speakers (G3) and so was the case of using well (Table 2). Figure 1 shows a word cloud in which the collocated and near-synonyms of well incidence in G1 are visualized. Figure 2 views the Arabic equivalents of well with reference to the source text of the corpus of translated novels.

It is obvious that Modern Standard Arabic demonstrates a lexical-pragmatic merging of terms which correspond to English pragmatic marker well. Colloquial Egyptian Arabic is more inclined to use pragmatic markers. Examples include 'tayyeb', 'mashy', 'kewayys', 'ya'ni', 'saheeh' and 'abadan'. The Arabic novels which are rich in colloquialism are more inclined to using pragmatic markers. Thus, rendering such markers into 'well' is more successful.

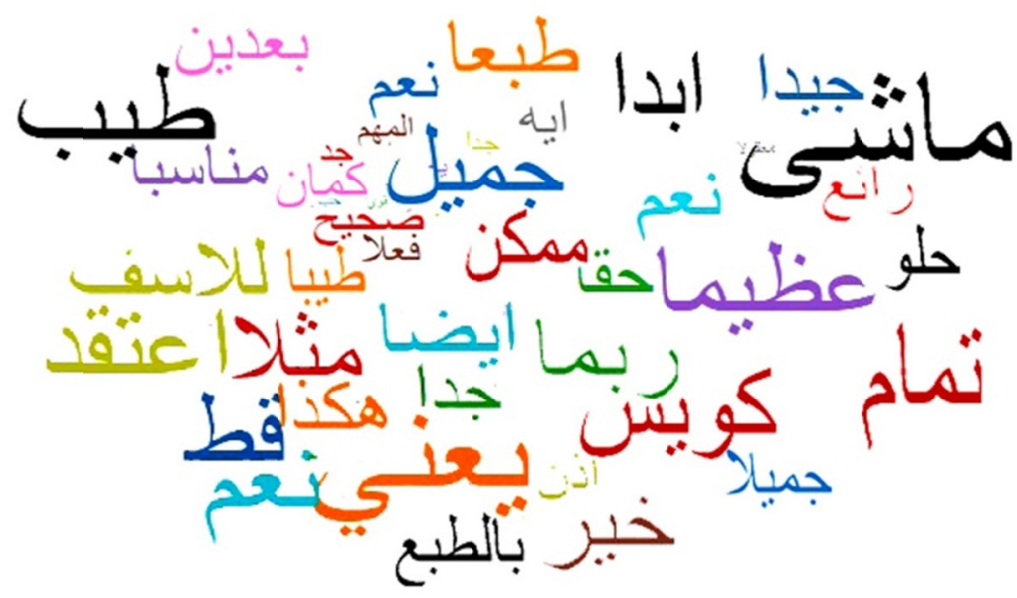

Figure 2. Arabic equivalents of well with reference to the source text of the translated 19 novels 
A one-way ANOVA test was run to measure the variance between the studied groups $(F=26.7323, p<0.05)$, suggesting that one or more groups are significantly different. The post-hoc Tukey HSD test identifies which of group pairs is significantly different from each other. Using the unified web-based phonotactic probability calculator, summed phoneme probabilities of representative examples of PPWs as well as their summed biphone probabilities are viewed. Pearson correlation co-eficient is 0.737 . Therefore, the correlation is strongly positive. Using either summation of phoneme or biphone probabilities is therefore accepted. On correlating the summed phoneme probabilities to the corresponding phoneme probabilities of the most familiar synonyms, the coorelation is weak positive but is statistically insignificant (Table 2).

Table 2. Representative examples of summed phoneme probabilities and summed biphone probabilities of PPWs

\begin{tabular}{|c|c|c|c|}
\hline Representative lemma & $\begin{array}{l}\text { Summed phoneme } \\
\text { probabilities }\end{array}$ & $\begin{array}{l}\begin{array}{l}\text { Summed biphone } \\
\text { probabilities }\end{array} \\
\end{array}$ & $\begin{array}{l}\text { Summed phoneme } \\
\text { probabilities of NS }\end{array}$ \\
\hline Camouflage & 1.2329 & 1.009 & 1.278 \\
\hline Cannonball & 1.371 & 1.0153 & 1.3458 \\
\hline Capitulate & 1.4227 & 1.0086 & 1.3261 \\
\hline Celibate & 1.3261 & 1.0144 & 1.2492 \\
\hline Chameleon & 1.2995 & 1.0086 & 1.3552 \\
\hline Chicanery & 1.2146 & 1.0056 & 1.2336 \\
\hline Chuckle & 1.1495 & 1.0051 & 1.3342 \\
\hline Circularize & 1.3342 & 1.0191 & 1.2187 \\
\hline Circulate & 1.3526 & 1.0059 & 1.3975 \\
\hline Circumambulate & 1.3975 & 1.004 & 1.1813 \\
\hline Clutch & 1.162 & 1.0046 & 1.4777 \\
\hline Combat & 1.2405 & 1.008 & 1.1447 \\
\hline Concurrent & 1.5375 & 1.0218 & 1.6421 \\
\hline Confiscate & 1.4135 & 1.0075 & 2.0576 \\
\hline Consanguineous & 1.6421 & 1.0179 & 1.2347 \\
\hline Constitutionalize & 2.0576 & 1.0548 & 1.0972 \\
\hline Convalesce & 1.3448 & 1.0105 & 1.3054 \\
\hline Convulse & 1.3113 & 1.0054 & 1.2008 \\
\hline Copulate & 1.3054 & 1.0073 & 1.2787 \\
\hline Counterbalance & 1.5748 & 1.011 & 1.1026 \\
\hline Curding & 1.2787 & 1.0085 & 1.219 \\
\hline Cruel & 1.1742 & 1.0051 & 1.1687 \\
\hline Crumble & 1.2452 & 1.0123 & 1.1138 \\
\hline Crumple & 1.2475 & 1.0133 & 1.2949 \\
\hline Cuddle & 1.1864 & 1.0056 & 1.2905 \\
\hline Culminate & 1.433 & 1.0093 & 1.2268 \\
\hline Cultivate & 1.4185 & 1.013 & 1.3011 \\
\hline Cumulate & 1.2905 & 1.0084 & 1.4979 \\
\hline Curdle & 1.2268 & 1.0074 & 1.1901 \\
\hline Diaspora & 1.1923 & 1.0113 & 1.4668 \\
\hline Dichotomy & 1.2023 & 1.0051 & 1.2111 \\
\hline Dictum & 1.1792 & 1.0035 & 1.0845 \\
\hline Diddle & 1.1901 & 1.0061 & 1.0962 \\
\hline Disarticulate & 1.4668 & 1.0152 & 1.463 \\
\hline Discharge & 1.2111 & 1.0056 & 1.278 \\
\hline Disgrace & 1.2227 & 1.0053 & 1.2135 \\
\hline Disparage & 1.2536 & 1.0154 & 1.1218 \\
\hline Disseminate & 1.5188 & 1.0076 & 1.3566 \\
\hline Dissimulate & 1.4144 & 1.0075 & 1.1951 \\
\hline Dissipate & 1.3935 & 1.0086 & 1.21 \\
\hline Divulge & 1.168 & 1.0035 & 1.3177 \\
\hline Dominion & 1.3923 & 1.0116 & 1.2801 \\
\hline Drastic & 1.2939 & 1.0245 & 1.1372 \\
\hline Dudgeon & 1.21 & 1.0041 & 1.2035 \\
\hline Duplicate & 1.3177 & 1.0102 & 1.1191 \\
\hline Ecclesiastic & 1.5368 & 1.0445 & 1.2762 \\
\hline Edith & 1.1372 & 1.0034 & 1.278 \\
\hline Emasculate & 1.3038 & 1.006 & 1.3458 \\
\hline Emulate & 1.2465 & 1.0076 & 1.3261 \\
\hline Encapsulate & 1.3477 & 1.006 & 1.2492 \\
\hline
\end{tabular}


Table 3. The incidence of using well and 'phonetically-problematic words' in the four studied groups

\begin{tabular}{|c|c|c|c|}
\hline \multirow[t]{2}{*}{ Work } & \multirow{2}{*}{$\begin{array}{l}\text { Hits } \\
\text { Well } \\
\end{array}$} & \multirow{2}{*}{$\begin{array}{l}\text { Proportions } \\
P P W s \\
\end{array}$} & \multirow[t]{2}{*}{ Translator(s) } \\
\hline & & & \\
\hline \multicolumn{4}{|c|}{ Control Group of Free English Writing (G1) } \\
\hline Lawrence's Women in Love & 0.004 & 0.003 & NA, (Original work) \\
\hline Clancy's Dead or Alive & 0.003 & 0.003 & NA, (Original work) \\
\hline Dicken's Great Expectation & 0.004 & 0.002 & NA, (Original work) \\
\hline John's Litigators & 0.002 & 0.002 & NA, (Original work) \\
\hline King's Under the Dome & 0.003 & 0.003 & NA, (Original work) \\
\hline James's Fifty Shades of Grey & 0.005 & 0.004 & NA, (Original work) \\
\hline \multicolumn{4}{|c|}{ Translations into English by native-speaking translators (G2) } \\
\hline Mahfouz's Respected Sir & 0.000 & 0.000 & A, Rasheed \\
\hline Mustaghenemi's Chaos of the Senses & 0.000 & 0.001 & A, Baria \\
\hline Mustaghenemi's Flesh in the Memory & 0.000 & 0.000 & A, Baria \\
\hline Mahfouz' Miramar & 0.001 & 0.001 & M, Fatma \\
\hline Barghouti's I saw Ramallah & 0.000 & 0.001 & S, Ahdaf \\
\hline Idris's Cheapest nights & 0.000 & 0.000 & W, Wadida \\
\hline Al-Ghitani's Zayni Barakat & 0.000 & 0.000 & Farouk Abdel Wahab \\
\hline Mahfouz's Akhenaten & 0.000 & 0.001 & Tagried Abu-Hassabo \\
\hline Mhafouz's the beginning and the Ending & 0.001 & 0.000 & Ramses Awad \\
\hline \multicolumn{4}{|c|}{ Translations into English by non-native-speaking translators (G3) } \\
\hline Taher's Sunset Oasis & 159 & 0.002 & W, Jonathon \\
\hline Taher's As Doha Said & 289 & 0.002 & T, Peter \\
\hline Mahfouz's Palace Walk & 426 & 0.003 & Hutchinson and Kate \\
\hline Mahfouz's Palace of Desire & 402 & 0.003 & Hutchinson and Kate \\
\hline Mahfouz's Children of the Alley & 304 & 0.002 & $\mathrm{~T}$, Peter \\
\hline Mahfouz's Midaq Alley & 271 & 0.003 & L, Petet \\
\hline Mahfouz's The Time and The Place & 340 & 0.002 & Denys Johnson-Davies \\
\hline Mahfouz's Wedding Song & 98 & 0.003 & Olive E. Kennry \\
\hline \multicolumn{4}{|c|}{ Translations into English by NT and NNT (G4) } \\
\hline Mahfouz's The Beggar & 0.002 & 0.002 & Henry and al-Waraki \\
\hline Mahfouz's The Thief and The Dogs & 0.003 & 0.002 & Trevor Le Gassick and M. M. Badawi \\
\hline
\end{tabular}

Note. Abbreviations: G: group; PPWs: Phonetically-problematic words.

Table 4. Results of Tukey HSD test among the studied groups

\begin{tabular}{lll}
\hline Group pairs & $\begin{array}{l}\text { Tukey HSD } \\
\text { Q statistic }\end{array}$ & $\begin{array}{l}\text { Corresponding } \\
\boldsymbol{p} \text {-value }\end{array}$ \\
\hline G1 vs G2 & 1.5059 & 0.6953226 \\
G1 vs G3 & 11.0588 & $0.0010053^{* *}$ \\
G1 vs G4 & 2.4901 & 0.3192938 \\
G3 vs NT & 10.3212 & $0.0010053^{* *}$ \\
G3 vs G4 & 4.8549 & $0.0123272^{*}$ \\
G2 vs G4 & 1.5431 & 0.6809538 \\
\hline
\end{tabular}

Table 4 demonstrates the statistical significance between the produce of the Arabic translators, in terms of using the PPWs, and the works in which they jointly participate $(p$-value $<0.05)$. Given this statistical significance, the null hypothesis, stating that there is no difference between the two studied groups, is rejected. This implies that the collaboration between Arabic and English translators improves the quality of the final product (G4). Nonetheless, there is no statistical significance between the production of the English translators, in terms of using the same set of words, and the native authors ( $p$-value $>0.05)$. Given the statistical insignificance of this test, the null hypothesis, stating that there is no difference between these two studied groups, cannot be rejected. This implies that the English writers express such sets of words in both free and controlled writings. However, the incidence of use the annotated set of words by the Arabic translators, on the one hand, and the English writers, either authors or translators, on the other hand, is highly significant ( $p$-value $>0.01$ ). This may reveal the unnaturalness of the Arabic translators' product to English readers."

\section{Discussion}

Tavangar (2003) investigates some of the problems involved in translating foregrounded lexical items within the 
domain of literary discourse: foregrounded through phonological, morphological and/or semantic motivation. In the same vessel, this study aims at measuring the impact of pragmatic markers acquisition and phonological awareness of non-native speaking and native-speaking translators on translating literary texts from Arabic into English.

According to Ellis (2006), selective attention and transfer phenomena in L2 acquisition include contingency, cue competition, salience, interference, overshadowing, blocking, and perceptual learning. Extrapolating from the above-mentioned results, the Arab translators seem to put most of these techniques into action when it comes to phonetically problematic words. Results reveal a significant distinction between native-speaking and non-native speaking translators in the use of the appended list of words. Both native translators and writers almost equally activate this list. Arabic translators, however, rarely summon the words which violate their Arabic phonetic rules.

The Arab speakers, on studying EFL, show problems with pronouncing long vowels and several consonant clusters (Fender, 2008). Saigh and Schmitt (2012) concluded that Arab ESL learners demonstrate greater difficulties with English spelling, compared to any other ESL learner group, which consequently affects their word recognition ability. Exemplary words include meek /'mi:k/ and reek/'ri: $\mathrm{k} /$. This is complicated when it comes to repeating vowels at short distances. Examples include peculiar/pı'kyulyər/ and cumulate /'kju:mjə, lert/. Also, they have problems with pronouncing the sounds /(s)trs/,/'sp/, /skw-/ and /-kstr-/. Examples of words which contain these sounds include squirm, exquisite, extraditable, extradite, extrapolate, perplexed, squabble, spatter, spawn, sprawl, spree, sprinkle, sprint, spritz, sprout, spruce, spud and spume. Accordingly, it is not unexpected from Arabic translators to avoid words that may have such hard-to-pronounce sounds especially when it comes to adding problematic vowels to such sounds.

As displayed in Table 3, non-native-speaking translators (G3) use the PPWs in a much lesser incidence than that of the peer native-speaking translators (G2). This is mitigated in G4. Therefore, the infrequent use of difficult-to-pronounce words (Appendix A) is attributed to the lower phonological awareness of such PPWs.

Although several studies suggest that phonological awareness with English phonotactics and phoneme co-occurrence, can interfere with learners' abilities to segment words from running speech using purely statistical cues at initial exposure and can mediate the influence of phonotactic probability (Endress et al., 2010; Finn \& Kam, 2008; Munson et al., 2005; Parra et al., 2011), the participants of such studies mentioned above were children. Postulating that translators exercise the same learning mechanism in studying L2, this study investigates the influence of the use of English pragmatic markers and of phonological awareness of English phonotactics by non-native speaking and native-speaking translators on translating literary texts from Arabic into English.

We agree with Nadeau (2001) that linguistic theories provide unsatisfactory accounts for the phonological processing. This rings true especially with explaining the occurrence of paraphasic errors that have both semantic and phonological similarity as well as cross-linguistic phonemes processing and production. Therefore, the integration of neurolinguistics evidence and basic theoretical and applied phonetics should be aimed to get a better understanding of the findings that neither sides can explain on its own.

\section{Conclusion}

This study suggests that the sensitive use of pragmatic markers on translating from Arabic into English can influence the readability of the English translation. Modern standard Arabic demonstrates a lexical-pragmatic merging of terms which correspond to English pragmatic markers. Colloquial Egyptian Arabic is more inclined to use pragmatic marker well. Colloquial Egyptian Arabic is more inclined to use pragmatic markers. Examples include 'tayyeb', 'mashy', 'kewayys','ya'ni' and 'abadan'. However, the use of such marker is case-sensitive and is bound to the context and genre of the studied literary text. We also conclude that phonological awareness of PPWs affect word choices among the studied groups of translators. This has implicated on the overall quality of the rendered translation in G3. Appendix 1 defines a list of PPWs which are rarely observed in the translations rendered by L1 Arabic translators.

Such findings should be further experimented in Arabic and English free writing. Other phonetically problematic English patterns (e.g., vowel combinations) should be checked in the Arabic translations of both native English and Arabic translators and so are gender difference and age effect in applying phonotactics to English production. The findings of this study should be validated in experimental studies and in ERP tasks. Reflection on the mental lexicon of Arabic learners of English language should be made. Accordingly, the attached appendix of non-primed words, in the Arabic mental lexicon, is recommended to be used whenever indicated should they choose to should they choose to achieve a native tone. 
Limitations of this study include studying translated novels which are written mostly by Egyptian authors (e.g., Mahfouz and Taher) and are translated by the few publishers (e.g., American University in Cairo). Studying literary texts originally written by multi-cultural Arabic writers (e.g., Saudi and Iraqi writers) would suggest more reliable results. The level of evidence introduced by the present is the least empirical evidence because it is only based on corpus-analysis of written texts and a web-based phontactic analyzer.

\section{References}

Aboul-Fetouh, H. M. (2017). A morphological study of Egyptian Colloquial Arabic (Vol. 33). Walter de Gruyter $\mathrm{GmbH} \& \mathrm{Co} \mathrm{KG}$.

Aijmer, K. (2013). Understanding pragmatic markers: a variational pragmatic approach. Edinburgh University Press.

Aijmer, K. (2015). Analysing Discourse Markers in Spoken Corpora: Actually as a Case Study. In B. Paul \& M. BakerTony (Eds.), Corpora and Discourse Studies (pp. 88-109). UK: Palgrave Macmillan. https://doi.org/10.1057/9781137431738_5

Aljasser, F., \& Vitevitch, M. S. (2018). A Web-based interface to calculate phonotactic probability for words and nonwords in Modern Standard Arabic. Behavior Research Methods, 50(1), 313-322. https://doi.org/10.3758/s13428-017-0872-z

Alós, J. (2016). Discourse relation recognition in translation: A relevance-theory perspective. Perspectives, 24(2), 201-217. https://doi.org/10.1080/0907676X.2015.1042391

Badecker, W. (1996). Representational properties common to phonological and orthographic output systems. Lingua, 99(1), 55-83. https://doi.org/10.1016/0024-3841(96)00005-8

Beeston, A. F. L. (2016). The Arabic language today. Routledge. https://doi.org/10.4324/9781315512815

Broselow, E. (2017). Syllable structure in the dialects of Arabic. In B. Elabbas \& B. Reem (Eds.), the Routledge Handbook of Arabic Linguistics (pp. 32-47). Routledge. https://doi.org/10.4324/9781315147062-3

Cuenca, M. J. (2008). Pragmatic markers in contrast: The case of well. Journal of Pragmatics, 40(8), 1373-1391. https://doi.org/10.1016/j.pragma.2008.02.013

Edwards, J., \& Zampini, M. (2008). Phonology and second language acquisition. John Benjamins Publishing. https://doi.org/10.1075/sibil.36

Ellis, N. C. (2006). Selective attention and transfer phenomena in L2 acquisition: Contingency, cue competition, salience, interference, overshadowing, blocking, and perceptual learning. Applied Linguistics, 27(2), 164194. https://doi.org/10.1093/applin/aml015

Endress, A. D., \& Jacques, M. (2010). Perceptual constraints in phonotactic learning. Journal of Experimental Psychology: Human Perception and Performance, 36(1), 235.

Fender, M. (2008). Spelling knowledge and reading development: Insights from Arab ESL learners. Reading in a foreign language, 20(1), 19.

Finn, A. S., \& Kam, C. L. H. (2008). The curse of knowledge: First language knowledge impairs adult learners' use of novel statistics for word segmentation. Cognition, 108(2), 477-499. https://doi.org/10.1016/j.cognition.2008.04.002

House, J. (2013). Developing pragmatic competence in English as a lingua franca: Using discourse markers to express (inter) subjectivity and connectivity. Journal of Pragmatics, 59, 57-67. https://doi.org/10.1016/j.pragma.2013.03.001

Kenworthy, J. (1987). Teaching English Pronunciation. London: Longman.

Mateo, M. (2014). Exploring Pragmatics and Phonetics for Successful Translation. Vigo International Journal of Applied Linguistics, 11, 111-135.

Metsä-Ketelä, M. (2016). Pragmatic vagueness: Exploring general extenders in English as a lingua franca. Intercultural Pragmatics, 13(3), 325-351. https://doi.org/10.1515/ip-2016-0014

Munson, B., Kurtz, B. A., \& Windsor, J. (2005). The influence of vocabulary size, phonotactic probability, and wordlikeness on nonword repetitions of children with and without specific language impairment. Journal of Speech, Language, and Hearing Research, 48(5), 1033-1047. https://doi.org/10.1044/1092-4388(2005/072)

Nadeau, S. E. (2001). Phonology: A review and proposals from a connectionist perspective. Brain and 
Language, 79(3), 511-579. https://doi.org/10.1006/brln.2001.2566

Nord, C. (2014). Translating as a purposeful activity: Functionalist approaches explained. Routledge. https://doi.org/10.4324/9781315760506

Norrick, N. R. (2009). Interjections as pragmatic markers. Journal of Pragmatics, 41(5), 866-891. https://doi.org/10.1016/j.pragma.2008.08.005

Parra, M., Hoff, E., \& Core, C. (2011). Relations among language exposure, phonological memory, and language development in Spanish-English bilingually developing 2-year-olds. Journal of experimental child psychology, 108(1), 113-125. https://doi.org/10.1016/j.jecp.2010.07.011

Peterlin, A. P., \& Moe, M. Z. (2016). Translating hedging devices in news discourse. Journal of Pragmatics, 102, 1-12. https://doi.org/10.1016/j.pragma.2016.06.009

Rinne, J. O., Tommola, J., Laine, M., Krause, B. J., Schmidt, D., Kaasinen, V., ... \& Sunnari, M. (2000). The translating brain: cerebral activation patterns during simultaneous interpreting. Neuroscience letters, 294(2), 85-88. https://doi.org/10.1016/S0304-3940(00)01540-8

Saigh, K., \& Schmitt, N. (2012). Difficulties with vocabulary word form: The case of Arabic ESL learners. System, 40(1), 24-36. https://doi.org/10.1016/j.system.2012.01.005

Storkel, H. L. (2001). Learning new words: Phonotactic probability in language development. Journal of Speech, Language, and Hearing Research, 44, 1321-1337. https://doi.org/10.1044/1092-4388(2001/103)

Storkel, H. L., Armbruster, J., \& Hogan, T. P. (2006). Differentiating phonotactic probability and neighborhood density in adult word learning. Journal of Speech, Language, and Hearing Research, 49, 1175-1192. https://doi.org/10.1044/1092-4388(2006/085)

Tavangar, M. (2003). Lexical Foregrounding: A perennial problem in translating literary communication. Babel, 49(2), 164-184. https://doi.org/10.1075/babel.49.2.05tav

Veroude, K., Norris, D. G., Shumskaya, E., Gullberg, M., \& Indefrey, P. (2010). Functional connectivity between brain regions involved in learning words of a new language. Brain and Language, 113(1), 21-27. https://doi.org/10.1016/j.bandl.2009.12.005

Vitevitch, M. S., \& Luce, P. A. (2004). A Web-based interface to calculate phonotactic probability for words and nonwords in English. Behavior Research Methods, Instruments, and Computers, 36, 481-487. https://doi.org/10.3758/BF03195594

Vitevitch, M. S., \& Luce, P. A. (2005). Increases in phonotactic probability facilitate spoken nonword repetition. Journal of Memory and Language, 52, 193-204. https://doi.org/10.1016/j.jml.2004.10.003

Wolter, J. A., \& Apel, K. (2010). Initial acquisition of mental graphemic representations in children with language impairment. Journal of Speech, Language, and Hearing Research, 53(1), 179-195. https://doi.org/10.1044/1092-4388(2009/07-0130)

\section{Appendix A}

\section{List of the compiled phonetically-problematic lemmas}

Acquaint*, Acquiescent*, Adolescence*, Adulate*, Adulterat*, Aggrandi*, Aggravat*, Aggriev*, Ameliorat*, Antiquat*, Apprentice, Appropriate, Articulat*, Auscultat*, Automobile, Avuls*, Awkward, Badger*, Bandit, Bawl*, Befuddl*, Beguil*, Bludgeon*, Blurr*, Bombast*, B*urgeon*, Brattl*, Brew*, Brim*, Brittle, Brusque, Brutali*, Bubble*, Buckle*, Bud*, Bulg*, Bulldoze*, Bumbl*, Bund1*, Bungl*, Burble*, Burglarize*, Burgl*, Burlesque, Burp*, Burr*, Bustle*, Camouflage*, Cannibal*, Capitulat*, Celibat*, Chameleon*, Cheek-fite, Chicanery*, Chuckl*, Circulari*, Circulat*, Circumambulat*, Clutch*, Combat*, Concurrent, Confiscat*, Consanguin*, Constitutionali*, Convalescent*, Convuls*, Copulat*, Coquettish, Counterbalanc*, Crudd*, Cruel*, Crumbl*, Crumpl*, Cuddl*, Culminat*, Cultivat*, Cumulat*, Curdl*, Deliquescen*, Diaspora, Dichotom*, Dictum*, Diddl*, Disarticulat*, Discharg*, Disgrac*, Disparag*, Disqualif*, Disseminat*, Dissimulat*, Dissipat*, Divulg*, Dominion, Drastic*, Dudgeon*, Duplicate*, Ecclesiasti*, Edith*, Elastize*, Emasculat*, Emulat*, Encapsulat*, Enthusiasti*, Enucleat*, Equali*, Erudit*, Eschatologi*, Eschew*, Escort*, Escutcheon*, Eulogi*, Evanescen*, Exasperat*, Excrescen*, Exculpat*, Exhilarat*, Expostulat*, Exquisit*, Extradita*, Extradite, Extrapolat*, Ferocious*, Fettle, Fiddl*, Flail*, Formulari*, Formulat*, Fuddl*, Fulminat*, Fumble, Furr, Furrow, Furtive, Gauge, Gaw*, Gigantic*, Gigantism*, Giggle*, Giggle*, Gossip*, Grandiose*, Grappa*, Griddle*, Grotesque*, Growli*, Grumble*, Gruntle*, Gudgeon*, Gurgle*, Guzzle*, Gymnastic*, 
Haw*, Hawke*, Hedonism*, Hickup*, Hitherto*, Holistic*, Homoplastic*, Huddl*, Humble*, Hurdle, Hurtle*, Hustle*, Hypothe*, Imminent*, Incandescen*, Incriminat*, Inculcat*, Inculpat*, Individuali*, Indubite, Indulg*, Industriali*, Inoculat*, Inosculat*, Insofar, Instigat*, Institutionali*, Insufflate*, Insulate*, Insurrect*, Intermingle*, Intumescent*, Iridescent*, Jeopardi*, Jig*, Jiggle*, Jigsaw*, Jocundity, Jubile*, Judder*, Juggle*, Julienne*, Jumble*, Jurisprudence*, Juvenescent*, Kettle*, Kittle*, Knuckle*, Lassitude, Lickspittl*, Lidded*, Liquescen*, Luminescen*, Macabre, Matriculat*, Mawkish*, Mediocre, Meek*, Mettle, Middleware*, Middling*, Miscalculate*, Modicum, Modulat*, Monumental*, Mottle*, Mud*, Muffle*, Mumble*, Mutilate*, Muzzle*, Necessi*, Nettle*, Neutrali*, Nighthaw*, Nightmari*, Nuzzle*, Obsolescen*, Onomastic*, Opalescen*, Osculat*, Outbalance*, Outlin*, Outliv*, Overindulg*, Overridden*, Overrule*, Painstaking, Pantheon*, Particulari*, Pastiche, Paucity, Pauling, Paulownia, Paunch*, Pauperi*, Peculiar*, Peddle*, Pentlandit*, Perambulate*, Perch*, Perplex*, Phosphorescent, Picaresque*, Picturesque*, Piddl*, Placid*, Plateaus*, Pleonasm*, Pleonastic*, Plethora*, Pliant*, Pontificat*, Populari*, Postulat*, Poultice*, Prattle, Preadolescen*, Prepubescen*, Procrastinat*, Prodigy*, Prognosticat*, Promulgate*, Pubescen*, Publici*, Pud*, Pullulat*, Pulsat*, Pulveri*, Purr*, Putrescen*, Putridity*, Puzzle*, Quever*, Quadruplicat*, Quaff*, Quail*, Quake*, Quanti*, Quarantine*, Quarrel*, Quash*, Quibble*, Quiddity*, Quiescent*, Quintuple*, Quirk*, Rambl*, Rancidity, Ratchet*, Ratiocinat*, Rattle*, Rebar*, Rebuk*, Rebut*, Recalculat*, Recapitulat*, Reckon*, Recon*, Recondite*, Reconstruct*, Recrudescent*, Recurr*, Redouble*, Reduplicate*, Reek*, Reformulat*, Regulari*, Repertoire*, Replicon*, Reprov*, Reschedule*, Resettle*, Reshuffle*, Restrict*, Restructure*, Resurrected*, Reticulate*, Retrospect*, Riddance*, Riddle*, Ridicule*, Ritualize*, Roundabout*, Rubicon*, Rubrice*, Ruckle*, Ruddere*, Rudd*, Ruffle*, Rumble*, Ruminat*, Rumple*, Rusticat*, Rustle*, Salien*, Scebled*, Scactere*, Schematize*, Schlep*, Schmooze*, Scholastic*, Scout*, Scowing*, Screech*, Scruple*, Scud*, Scuffle*, Sculptur*, Scurrilous*, Scurry*, Scuttle*, Seattle*, Seculari*, Senescen*, Servility*, Shroud*, Shrug*, Shudder*, Shuffle*, Shuttle*, Simulat*, Singulariz*, Skid*, Skittle*, Slink*, Slit*, Slither*, Slitt*, Sloth*, Slumbering*, Slur, Smuggl*, Snuffl*, Snuggl*, Soaplather*, Sophisticat*, Spaizing, Spangle*, Spar*, Sparkle*, Spas*, Spat*, Spawn*, Spearhead*, Speckle*, Specs, Spectacular*, Speculate*, Speechify*, Spew*, Spike*, Spine*, Spiral*, Spiritual*, Spit*, Spittle*, Splash*, Splat*, Splay*, Splice*, Splint*, Splinter*, Split*, Splotch*, Splurge*, Splutter*, Spoil*, Sponge*, Spoof*, Spool*, Spoon*, Spout*, Sprain*, Sprawl*, Spray*, Spree*, Spring*, Sprinkle*, Sprint*, Spritz*, Sprout*, Spruce*, Spud*, Spume*, Spur*, Spurt*, Sputter*, Squabble*, Squeal*, Squall*, Squander*, Squash*, Squat*, Squaw*, Squawker*, Squirm*, Statuesque*, Stimulate*, Stipulate*, Stochastic*, Stochastically*, Stooped*, Straddle*, Straddling*, Strafe*, Straightedge*, Straighten*, Straightly*, Straightness*, Strain*, Strait*, Strake*, Strand*, Strangle*, Strangulate*, Strappy*, Stratag*, Stratif*, Stridden*, Stridulate*, Structure*, Stud*, Stumble*, Stump*, Stupor*, Suable*, Suasion*, Suav*, Subcontract*, Sublease*, Subtilize*, Subtract*, Suckle*, Suddenness, Sump*, Supple*, Supplicate*, Surrealis*, Surreptitious*, Surreptiti*, Surrogat*, Susurrat*, Svelte*, Swamp*, Tabulari*, Tabulat*, Tamp*, Tantali*, Tattle*, Teakettle*, Telecast*, Telepath*, Tendril*, Tentati*, Terrain*, Throated, Throbb*, Throne, Throng*, Throttle*, Thud*, Tincture*, Tittle*, Tousle*, Tramp*, Tranquil*, Transact*, Translocate*, Triangulate*, Trifurcate*, Triplicate*, Trisect*, Trod*, Trolled*, Tromp*, Troop*, Trot*, Troth*, Troubleshoot*, Troublesome*, Trough*, Trounce*, Troupe*, Trousers*, Trousseau*, Trout*, Truckl*, Trump*, Truncat*, Truncheon*, Trundle*, Tuberous*, Tumble*, Tumescen*, Tumultuous, Tussle*, Twinkle*, Ululate*, Unbalance*, Unbuckle*, Underlie*, Underline*, Undervalue*, Undoubted*, Undulate*, Unfathomed*, Unsettle*, Untangle*, Utilize*, Vagran*, Vicissitude*, Vineyard, Visualize*, Voluptuous*, Vulcani*, Vulgar*, Vulnerabl*, Waft*, Wasps*, Wattle*, Whittle*, Wimp*, Wisp*, Wither*, Workaholic.

(*) The asterisk denotes any morphological affix which can be suffixed to the lemma for encoding a syntactic function.

\section{Copyrights}

Copyright for this article is retained by the author, with first publication rights granted to the journal.

This is an open-access article distributed under the terms and conditions of the Creative Commons Attribution license (http://creativecommons.org/licenses/by/4.0/). 